This item was submitted to Loughborough's Research Repository by the author.

Items in Figshare are protected by copyright, with all rights reserved, unless otherwise indicated.

\title{
Finite element simulations of conventional and ultrasonically assisted turning processes with plane and textured cutting inserts
}

\author{
PLEASE CITE THE PUBLISHED VERSION
}

https://doi.org/10.1177/2516598419878022

\section{PUBLISHER}

SAGE Publications

VERSION

AM (Accepted Manuscript)

\section{PUBLISHER STATEMENT}

This paper was accepted for publication in the journal Journal of Micromanufacturing and the definitive published version is available at https://doi.org/10.1177/2516598419878022. Users who receive access to an article through a repository are reminded that the article is protected by copyright and reuse is restricted to non-commercial and no derivative uses. Users may also download and save a local copy of an article accessed in an institutional repository for the user's personal reference.

\section{LICENCE}

CC BY-NC-ND 4.0

\section{REPOSITORY RECORD}

Sharma, Varun, Pulak M Pandey, Uday S Dixit, Anish Roy, and Vadim Silberschmidt. 2019. "Finite Element Simulations of Conventional and Ultrasonically Assisted Turning Processes with Plane and Textured Cutting Inserts". Loughborough University. 


\title{
Finite element simulations of conventional and ultrasonically assisted turning processes with plane and textured cutting inserts
}

\author{
Varun Sharma', Pulak M. Pandey², Uday S. Dixit ${ }^{3}$, Anish Roy ${ }^{4}$, and Vadim V. \\ Silberschmidt ${ }^{4}$
}

\begin{abstract}
This paper investigates the performance of conventional turning and ultrasonically assisted turning (UAT) processes with plane and textured cutting inserts. Simulations based on the finite-element method were carried out using a software package ABAQUS/Explicit (Dassault Systemes, France). The obtained results were validated experimentally by employing a specially developed UAT setup. The purpose of the paper is to analyze cutting-force variation by the use of textured cutting inserts. Optimized dimensions of the texture pattern were used to model textured cutting inserts. The cutting-force variation in UAT was assessed with finite-element method, confirming diminishing cutting forces at a tool-workpiece interface during a noncontact time. The use of the textured cutting inserts in the UAT process resulted in the lowest cutting forces when compared to a plane tool in UAT as well as both plane and textured tools in the conventional turning process.
\end{abstract}

\section{Keywords}

Simulation, textured, cutting force, conventional turning, ultrasonically assisted turning

\section{Nomenclature}

$\begin{array}{ll}\varepsilon^{f} & \text { Fracture strain } \\ \dot{\varepsilon} & \text { Strain rate } \\ \dot{\varepsilon}_{0} & \text { Reference strain rate } \\ \varepsilon_{p} & \text { Plastic strain } \\ \varepsilon_{x}, \varepsilon_{y}, \varepsilon_{z} & \text { Strain in X,Y and Z direction } \\ \xi_{i}, \eta_{i} & \text { Natural co-ordinates of the } i \text { th element } \\ \mu & \text { node } \\ \rho & \text { Coefficient of friction } \\ \bar{\sigma} & \text { Density } \\ \omega & \text { Equivalent stress } \\ a & \text { Angular frequency } \\ A & \text { Amplitude of vibration } \\ B & \text { Initial yield stress } \\ B & \text { Hardening modulus } \\ C_{p} & \text { Strain displacement matrix } \\ D & \text { Specific heat } \\ D_{1} & \text { Elasticity matrix } \\ D_{2} & \text { Initial failure strain } \\ D_{3} & \text { Exponential factor } \\ D_{4} & \text { Tri-axiality factor } \\ D_{5} & \text { Strain-rate factor } \\ & \text { Temperature factor }\end{array}$

\begin{abstract}
Young's modulus
Frequency of vibration

Bulk modulus

Parameter related to acoustic softening

Thermal softening coefficient

Interpolation or shape function

Vector of nodal displacements

Operating temperature

Melting temperatures

Room temperatures

Displacement in $X$ axis

Displacement in $Y$ axis

Displacements at the $i$ th node along the global $X, Y$ axes
\end{abstract}

\footnotetext{
' Department of Mechanical and Industrial Engineering, IIT Roorkee, Uttarakhand, India

${ }^{2}$ Department of Mechanical Engineering, IIT Delhi, New Delhi, India

${ }^{3}$ Department of Mechanical Engineering, IIT Guwahati, Assam, India

${ }^{4}$ Wolfson School of Mechanical, Electrical and Manufacturing Engineering, Loughborough University, Loughborough, UK
}

\section{Corresponding author:}

Varun Sharma, Department of Mechanical and Industrial Engineering, IIT Roorkee, Roorkee, Uttarakhand 247667, India.

Email: varuns.fme@iitr.ac.in 


$\begin{array}{ll}u_{R 3} & \text { Rotation about } Z \text { axis } \\ U_{L} & \text { Vibration energy density } \\ V & \text { Cutting velocity } \\ V_{c} & \text { Cutting velocity in CT } \\ x_{i}, y_{i} & \text { Global x-y co-ordinates } \\ \Delta Y_{L} & \text { Reduction in yield strength } \\ Y_{L} & \text { Yield strength of material in surface layer } \\ & \text { with vibration } \\ Y_{o} & \text { Yield strength of material in surface layer } \\ & \text { without vibration }\end{array}$

\section{Abbreviations}

$\begin{array}{ll}\text { CT } & \text { Conventional turning } \\ \text { PCT } & \text { Plane tool in conventional turning } \\ \text { PUAT } & \text { Plain tool in ultrasonically assisted turning } \\ \text { TCT } & \text { Textured tool in conventional turning } \\ \text { TUAT } & \begin{array}{l}\text { Textured tool in ultrasonically assisted } \\ \text { turning }\end{array} \\ & \text { Ultrasonically assisted machining } \\ \text { UAM } & \text { Ultrasonically assisted turning }\end{array}$

\section{Introduction}

A challenge was posed to conventional turning (CT) process with the introduction of hard-to-cut structural materials due to high cutting forces accompanied with the intense heat generation in a process zone. Thus, research in recent years has focused on creating new environment friendly machining processes. In this regard, the minimum quantity lubrication and cryogenic cooling were used to eliminate the drawbacks of dry machining. Ultrasonically assisted machining (UAM) is a novel machining process developed recently. This process involves imparting high-frequency and low-amplitude vibration to the cutting tool. It was extensively used in turning, milling, and drilling processes to machine intractable materials.

In the late 1950s, one-dimensional (1D) ultrasonically assisted turning (UAT) was developed, mainly for machining of materials, not easily turnable by a diamond cutting tool. ${ }^{1}$ The process gained its popularity in the mid-1980s to machine steel, glass, and ceramics. However, with the advent of hardto-cut materials like Ni- and Ti-based alloys, the research efforts in the field of 1D UAT were intensified in the early 1990s. A vibro-impact mechanism, which is inherent to the UAT process, results in a periodic separation of a tool and a workpiece. This, in turn, helps to decrease the cutting forces over a complete cycle of vibration.

Mitofanov et al. ${ }^{2}$ were the pioneers in the development of a two-dimensional (2D) finite element (FE) model for the UAT process. They used the MSC Marc/Mentat FE code to provide a detailed cutting-force analysis during one cycle of ultrasonic vibration. They reported a single vibration cycle of UAT to be composed of four different stages - approach, toolchip contact, penetration, and unloading. In another research attempt, Mitrofanov et al. ${ }^{3}$ performed three-dimensional (3D) FE simulations to present a comparative analysis between the $\mathrm{CT}$ and UAT processes. The quasistatic cutting forces in CT were compared with varying ones in the UAT process. The FE analysis showed that lubrication in UAT resulted in a reduction in the cutting forces by $20-25 \%$ as compared to dry UAT.

Babitsky et al. ${ }^{4}$ performed numerical simulations of the UAT process using the MSC software. They reported higher cutting temperature during UAT as compared to the CT process; this was linked to the introduction of an additional energy due to the superimposition of ultrasonic vibration. Additionally, the effect of hot machining in conjunction with the UAT process was analyzed by Muhammad et al. ${ }^{5}$ The finite-element analysis showed a decrease in the tangential cutting force with a rise in the external heat supplied to the workpiece. The stress state in the hot UAT process was found to be transient in nature and changed during each cycle of vibration.

In another study, Ahmed et al. ${ }^{6}$ presented a 3D FE model using the MSC MARC/MENTAT FE software. The transient analysis of elastoplastic material was performed using an updated Lagrangian analysis approach. The results showed that the peak forces in UAT were about $40 \%$ higher than those in $\mathrm{CT}$, with a considerable reduction in the average magnitudes. However, the efficiency of the process should be based not merely on force comparison but also on the quality of machined surface. Patil et al. ${ }^{7}$ developed a 2D FE model to present a comparative analysis between CT and UAT processes. The simulation results were supported with experimental findings by imposing ultrasonic vibration in the feed direction.

Muhammad et al. ${ }^{8}$ performed FE simulations of oblique hot UAT of a Ti-based alloy by incorporating an increase in the workpiece temperature into the model. They used a modified shear-friction model to simulate friction between tool, chip, and workpiece interfaces. A significant decrease in the cutting force was reported for UAT. Several experimental investigations ${ }^{9-11}$ were also performed to analyze the benefits of the UAT process while machining Ni- and Ti-based alloys.

In a separate approach, researchers also tried to attain sustainable manufacturing by using textured cutting inserts. In this regard, experimental investigations ${ }^{12-16}$ were performed to machine intractable materials using self-lubricating cutting inserts. Ze et al. ${ }^{13}$ used a pulsating heat pipe to enhance the heat dissipation from a cutting insert while turning Ti6A14V. Self-lubricating cutting inserts fitted with such a heat pipe were found to reduce the friction coefficient by $5-20 \%$ as compared to the conventional tools.

Xie et al. ${ }^{17}$ employed microgrooved tools in the turning of a Ti-based alloy. They reported that a decrease in the aspect ratio of a groove resulted in an increase in the machining temperature. A reduction of about $56.1 \%$ in the main component of cutting force was observed using the developed cutting insert as compared to a plane cutting tool. Jianxin et al. ${ }^{18}$ analyzed the performance of carbide inserts embedded with solid lubricants. They reported that cutting forces, cutting temperature, and the coefficient of friction decreased 
substantially with the use of the textured cutting insert. The decrease in a tool-chip contact length accompanied with the formation of a thin lubrication layer diminished the frictional force at the tool-chip interface.

Kawasegi et al. ${ }^{19}$ developed micro- and nanoscale texture patterns on cutting tools using a femtosecond laser for machining an Al-based alloy. They reported a decrease in cutting forces due to a difference in the material adhereability at high cutting speed. Jiang et al. ${ }^{20}$ developed $3 \mathrm{D}$ coating with cBN particles on a TiN matrix to biomimic sea-urchin teeth. A superior tool life and better surface finish were reported for finish-turning of 4340 steel using such serrated cutting inserts.

Obikawa et al. ${ }^{21}$ created microtexture on a coated tool using photolithography and wet-etching. They reported that a smaller and deep microtexture pattern improved the effectiveness of lubrication in turning of an aluminum alloy A6061-T6. Wenlong et al. ${ }^{22}$ compared different solid lubricants in dry machining of hardened steel using cementedcarbide tools with microholes. $\mathrm{MoS}_{2}$ solid lubricant oxidized at high cutting temperature, whereas thanks to better physical properties of embedded $\mathrm{CaF}_{2}$, a cutting insert performed well even at high cutting speeds. An extensive research ${ }^{6-8,23-25,26}$ was carried out in FE simulations during $\mathrm{CT}$ and UAT processes. Recently, Goel et al. ${ }^{41}$ carried out a molecular dynamic simulation of 3D elliptical machining of body centered cubic iron. They reported lower cutting forces and coefficient of kinetic friction during elliptical machining than those in CT. However, vibrations enhanced the cutting temperature in the machining region.

It is well established that the UAT process can be characterized by four main stages. ${ }^{4}$ In Stage 1, the cutting tool is not in engagement with the workpiece, but is approaching it. The cutting tool penetrates into the workpiece in Stage 2, performing the cutting operation. Stage 3 is characterized by the tool retracting. In the last stage, the tool disengages after performing the cutting operation. The aerodynamic lubrication during the periods of tool separation from the chip helps to reduce the effective coefficient of friction. A recent study utilized the dual-benefit of aerodynamic lubrication (due to UAT) and the formation of a thin lubricating layer (due to texturing). ${ }^{27}$ Generally, UAT lowered average cutting forces, improved surface finish, and reduced tensile residual stresses in the workpiece. ${ }^{27,28}$
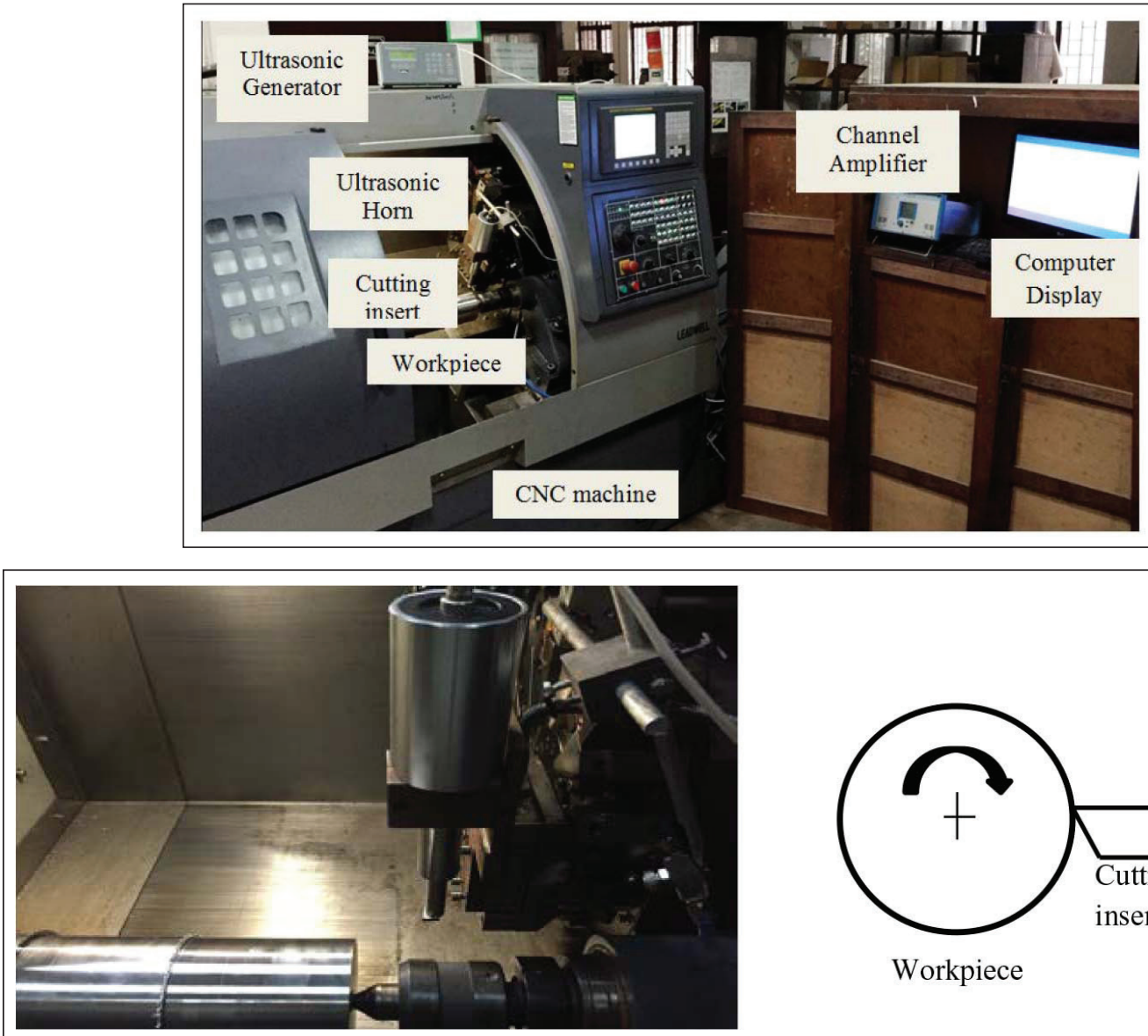

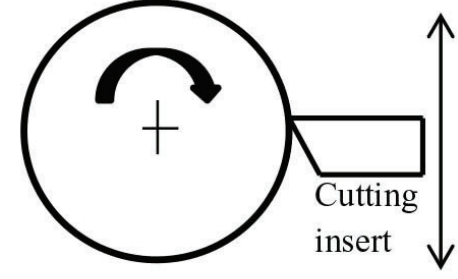

Workpiece
Ultrasonic vibration in cutting direction.

Figure I. Experimental setup for ultrasonically assisted turning (UAT) experimentation. ${ }^{31}$ 


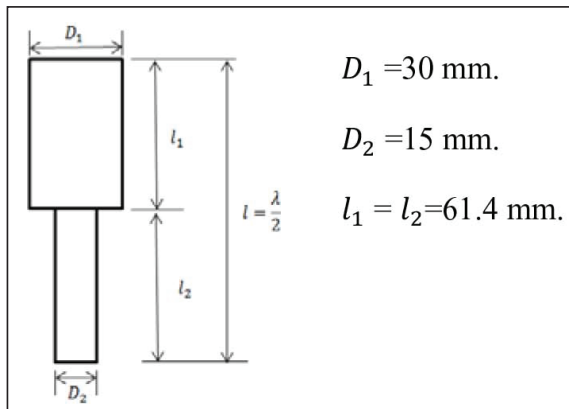

(a)

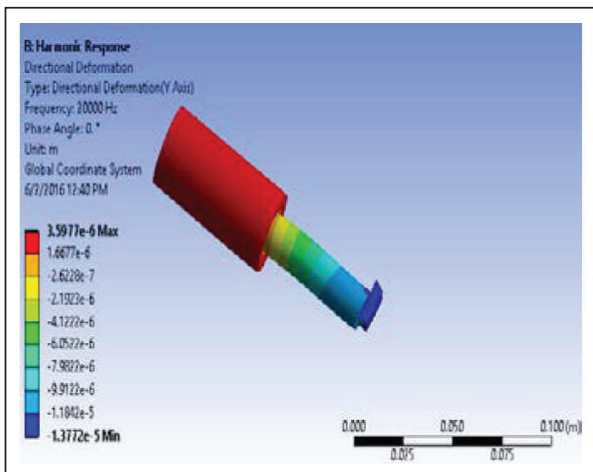

(c)

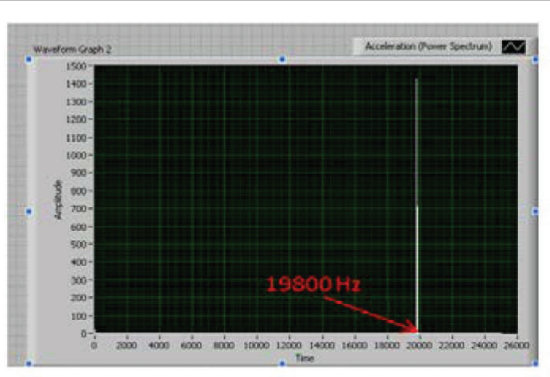

(e)

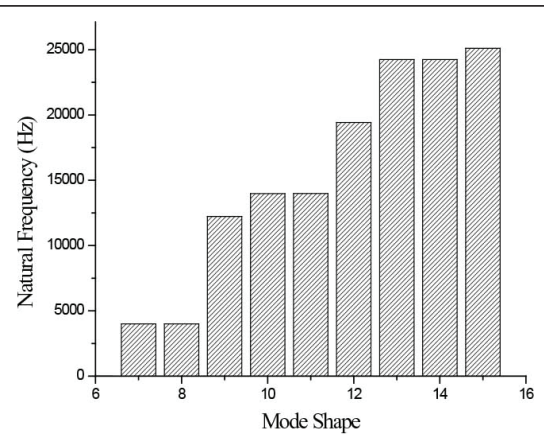

(b)

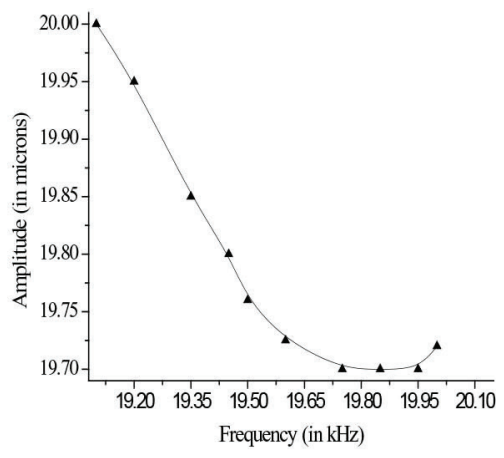

(d)

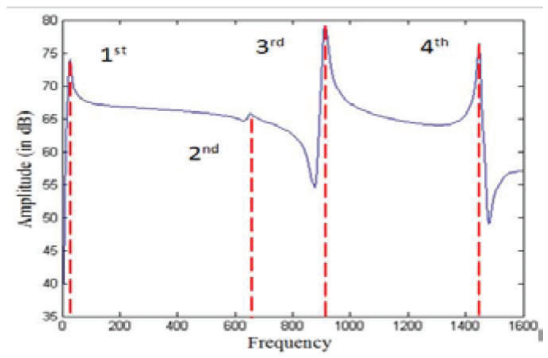

(f)

Figure 2. (a) Schematic of ultrasonic horn. (b) Mode shape versus natural frequency. (c) Harmonic analysis using ANSYS. (d) Amplitude versus frequency. (e) Natural frequency of horn measured with accelerometer. (f) Natural frequencies of the fixture. ${ }^{31}$

This work attempts to analyze the mechanism of a textured (TUAT UAT) process. The basis of this research is an experimental study that established benefits of the TUAT process in terms of lowering of cutting forces, surface roughness, and tensile residual stresses in comparison to plane tool in conventional turning (PCT), textured tool in conventional turning (TCT), and plain tool in ultrasonically assisted turning (PUAT) processes..$^{25,27-30}$ This paper fills a gap in the literature by presenting a $2 \mathrm{D}$ finite element method (FEM) simulation of this process. Although the turning process is inherently $3 \mathrm{D}$, a $2 \mathrm{D}$ analysis with an equivalent rake angle can elucidate the cutting process and provide sufficiently accurate quantitative predictions. The cutting forces are one of the influencing parameters that can be related to surface roughness, tool life, and material removal rate. A comparative analysis of the cutting forces is presented for CT and UAT performed with both plane and textured cutting inserts in terms. The simulated cutting forces obtained with a 2D FE model is then compared with the experimental findings for the cutting forces measured with an in-house UAT setup described in the following section.

\section{Experimental investigations}

Experimental studies were carried out to measure cutting forces in $\mathrm{CT}$ and UAT processes using plane and self-lubricating cutting inserts. A Kistler piezoelectric dynamometer (9129 AA) was used for the measurement of cutting forces during 
the turning operation. Each turning test was performed over a length of $15 \mathrm{~mm}$ and an average cutting force was evaluated.

Figure 1 shows the UAT system developed for present experimentation. Ultrasonic vibration was applied in the tangential direction (i.e., cutting direction) employing a customized stepped horn. The horn served as a means of transmitting the vibratory energy from the transducer's end to the other end, by providing a means for the wave propagation. The materials used for the fabrication of horn should have high impact strength and a low absorption coefficient. Out of various prescribed materials, stainless steel (SS316) was selected because of its availability and a lower cost as compared to titanium alloy. Horns could be manufactured in various shapes and dimensions; however, for ease in manufacturing, a stepped horn was made for providing vibration to the cutting insert. Figure 2(a) shows the design details of the fabricated stepped horn. It is a half wave stepped horn with an input diameter of $30 \mathrm{~mm}$ (which is the design limitation of booster) and output diameter of 15 $\mathrm{mm}$ designed for ultrasonic frequency of $20 \mathrm{kHz}$. The horn amplifies the amplitude of vibration by a factor of four (refer to Appendix A).

A modal analysis was performed using a general-purpose FE software, ANSYS, to reveal different mode shapes like torsional and bending of the developed ultrasonic horn. Modal analysis feature of ANSYS Workbench 18.1 is used to perform modal extraction for all the horns. An initial graphics exchange specifications (IGS) model file is imported using geometry import feature and an already defined ANSYS material structural steel is assigned. FEM requires mesh generation for analysis, which is generated using the mesh feature of modal analysis with fine mesh size and element defined by SOLID186. SOLID186 is used for 3D FE analysis of horn shapes. The element is defined using eight nodes with three degrees of freedom at each node. After mesh generation modes were extracted using Block Lanchozs method. It was found that its 12 th mode of vibration corresponded to the longitudinal mode of vibration with a natural frequency of $19.8 \mathrm{kHz}$ (refer to Figure 2[b]). Harmonic analysis was performed to study the amplification factor of the developed stepped horn; this factor was found to be approximately of the order of 4. From Figure 2(c) it can be seen that with an input of $3 \mu \mathrm{m}$ amplitude at the transducer end, the cutting insert experienced amplitude of $13.7 \mu \mathrm{m}$ corresponding to the 12 th mode of vibration.

Figure 2(d) shows the calibration of amplitude in terms of natural frequency. It could be deduced that with input amplitude of $5 \mu \mathrm{m}$ at the transducer end, the 12th mode of vibration (i.e., operating at $19.8 \mathrm{kHz}$ ) resulted in a maximum amplitude of $19.7 \mu \mathrm{m}$. Experimentally, the natural frequency of the developed horn was measured using an accelerometer and was found to be $19.8 \mathrm{kHz}$ (Figure 2[e]). The accelerometer (ACC 104, Make: Omega, sampling frequency range of $10,000)$ was mounted on the horn end (i.e., diameter of 15 $\mathrm{mm}$ ) using an adhesive. The ultrasonic horn was mounted on the lathe turret with a dynamometer, employing a customized jig plate. To prevent the condition of resonance, the frequency of the developed jig plate was measured using a hammer test. The instrumented hammer with a force transducer at impact tip was used to measure the third natural frequency of the plate of the order of $1000 \mathrm{~Hz}$ (Figure 2[f]), which was significantly lower than a natural frequency of the Kistler dynamometer (9129AA), $3.5 \mathrm{kHz}$. Thus, the condition of resonance in UAT experiments could be prevented.

Table 1 presents the cutting conditions used in experimentation. In cutting experiments, a cutting insert CNMA 120404 was used; it was easy to generate a texture pattern on this tool. Figure 3 presents the scanning electron microscope (SEM) image of textured cutting insert developed by the authors using a femto-second Nd-YAG laser. Dimensions of the optimized texture pattern obtained from a Taguchi-based design of experimentation are given in Table 2. The details of texture fabrication and design optimization can be found in other published articles. ${ }^{29,30}$

Table I. Experimental conditions for performed experimentation.

\begin{tabular}{ll}
\hline Tool geometry & $\begin{array}{l}\text { Approach angle } 95^{\circ}, \\
\text { Rake angle }-6^{\circ}, \\
\text { Nose radius } 0.4 \mathrm{~mm}\end{array}$ \\
Kistler Dynoware \\
Donamometer & $10-90 \mathrm{~m} \mathrm{~min}^{-1}$ \\
Cutting velocity & $0.2 \mathrm{~mm} \mathrm{rev}^{-1}$ \\
Feed rate & $0.1 \mathrm{~mm}$ \\
Depth of cut & \\
\hline
\end{tabular}

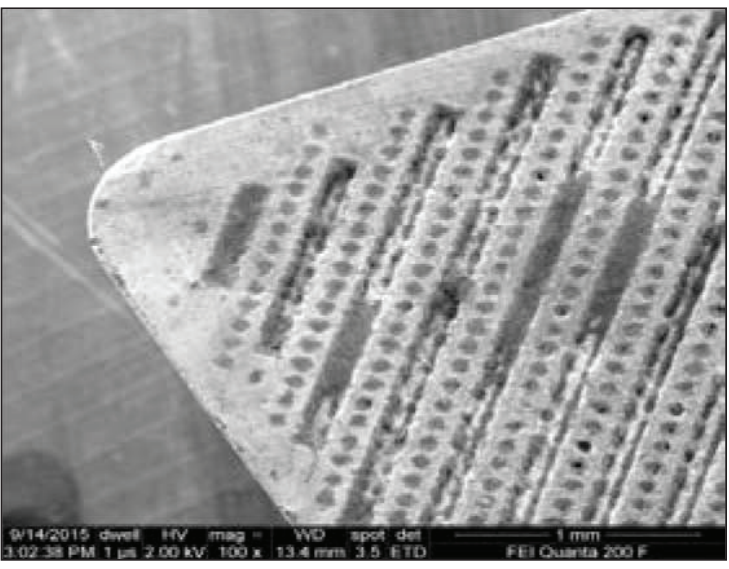

Figure 3. SEM image (at 100x) of hybrid textured cutting insert. ${ }^{31}$

Table 2. Optimum design parameters for textured cutting insert. ${ }^{30}$

\begin{tabular}{clc}
\hline S. no. & Design parameter & Magnitude $($ in $\mu \mathrm{m})$ \\
\hline I & Distance from cutting edge & 100 \\
2 & Width of rectangle & 100 \\
3 & Pitch & 360 \\
4 & Diameter of dimple & 100 \\
5 & Depth of texture & 140 \\
\hline
\end{tabular}




\section{Finite element model}

The FEM has been extensively used for modeling of machining processes. However, to the best of authors' knowledge, no FE model for UAT with a self-lubricating cutting insert has been developed. An Arbitrary Lagrangian-Eulerian method was used to model the process with a commercial FE package ABAQUS/Explicit version 6.13-1. Figure 4 shows a schematic of the workpiece and the tool used in simulations of the CT and UAT processes.

For the presented simulations, the workpiece was kept stationary, whereas the cutting tool was provided a linear cutting velocity in the CT process. For UAT, a periodic motion was superimposed on the linear cutting velocity of the cutting tool with a frequency and the amplitude of vibration of $19.8 \mathrm{kHz}$ and $12 \mu \mathrm{m}$, respectively. The following sections highlight a modeling methodology for the workpiece and the tool together with constitutive equations used in simulations.

\section{Geometric details and model assumptions}

A rectangular domain of the workpiece made of 4340 steel with dimensions as reported in Table 3 was involved in interaction with a deformable tool in the FE analysis. A fournoded bilinear plane-strain quadrilateral (CFE4R) element with hourglass control and reduced integration was used for meshing the tool and the workpiece. The workpiece was meshed with 12,000 elements with an approximate global size of $0.005 \mathrm{~mm}$, whereas 250 elements with a global size of $0.033 \mathrm{~mm}$ were created in the deformable tool (refer to Figure 5). Selection of the lubricant and the texture pattern was based on the experimental findings reported in the work by Sharma and Pandey. ${ }^{29}$ The 2D FE simulations approximated the geometry of dimples and grooves to provide a comparison for plane and textured tools by altering the tool-chip interface conditions based on the coefficient of friction. The physical and mechanical properties of materials used in tool and workpiece for the presented simulation are provided in Table 4.

Figure 6 shows the degrees of freedom (dofs) of the quadrilateral element. Element's geometry and its displacement fields are defined in terms of nodal coordinates and degrees of freedom by the following functions. ${ }^{33}$

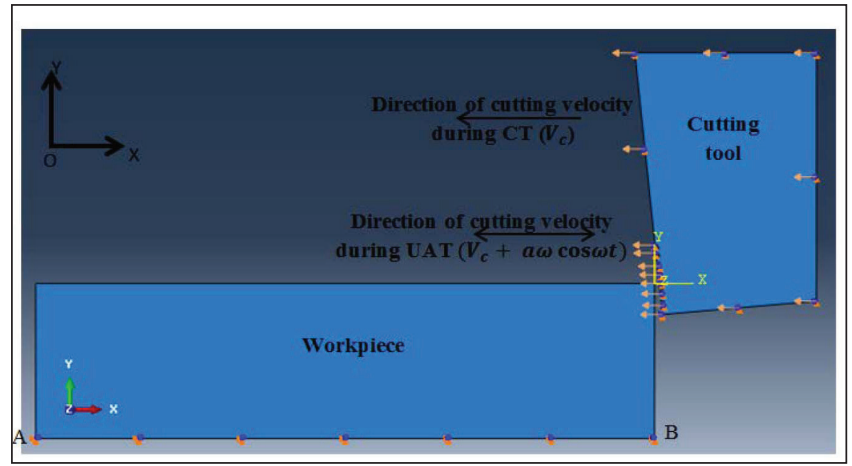

Figure 4. Tool-workpiece model with B.C.'s in ABAQUS.

Table 3. Tool, workpiece and cutting parameters.

\begin{tabular}{llc}
\hline Description & Parameter & Value \\
\hline Cutting tool & Rake angle & $-6^{\circ}$ \\
& Clearance angle & $5^{\circ}$ \\
Workpiece & Length $(\mathrm{mm})$ & 2 \\
& Width $(\mathrm{mm})$ & 0.4 \\
Cutting parameters & Cutting velocity $\left(\mathrm{m} \mathrm{min}{ }^{-1}\right)$ & 50,90 \\
& Uncut chip thickness $(\mathrm{mm})$ & 0.1 \\
\hline
\end{tabular}

Table 4. Physical and mechanical properties of workpiece and cutting tool.

\begin{tabular}{|c|c|c|c|c|c|c|}
\hline Material & $\begin{array}{c}\text { Density } \\
\rho\left(\mathrm{kg} \mathrm{m}^{-3}\right)\end{array}$ & $\begin{array}{c}\text { Young's modulus } E \\
(\mathrm{GPa})\end{array}$ & $\begin{array}{c}\text { Poisson's ratio } \\
\mu \\
\end{array}$ & $\begin{array}{c}\text { Bulk modulus } \\
K \\
\left(\mathrm{Wm}^{-1} \mathrm{~K}^{-1}\right)\end{array}$ & $\begin{array}{c}\text { Specific heat } \\
C_{p} \\
\left(\mathrm{~kg}^{-1} \mathrm{~K}^{-1}\right)\end{array}$ & $\begin{array}{c}\text { Melting temperature } \\
T_{\text {melt }}(\mathrm{K}) \\
\end{array}$ \\
\hline AISI 4340 & 7830 & 200 & 0.29 & 38 & 477 & 1793 \\
\hline Carbide tool & 11,900 & 534 & 0.22 & 50 & 400 & - \\
\hline
\end{tabular}

Source: Johnson and Cook. ${ }^{32}$

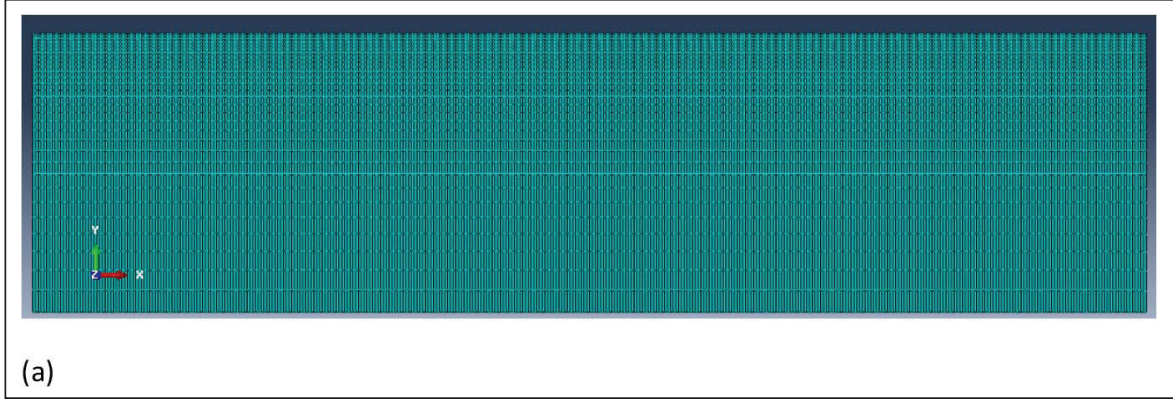




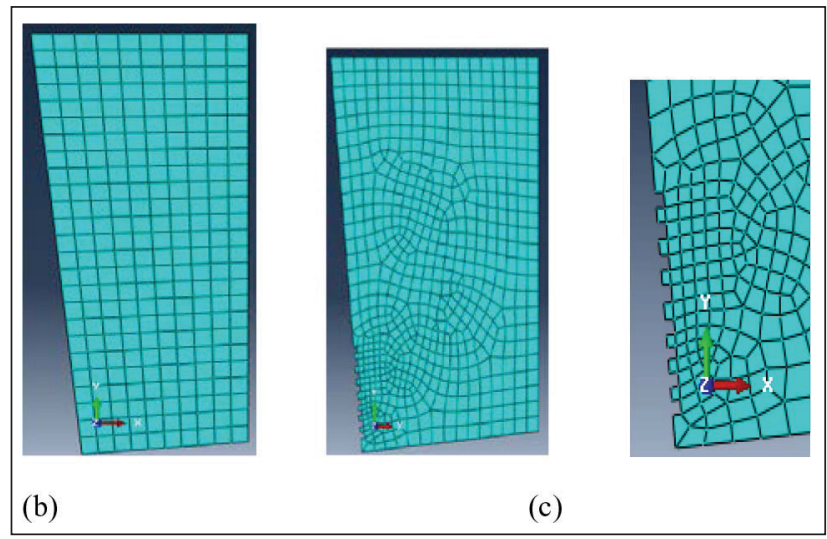

Figure 5. (a) Meshed workpiece. (b) Plane. (c) Textured inserts.

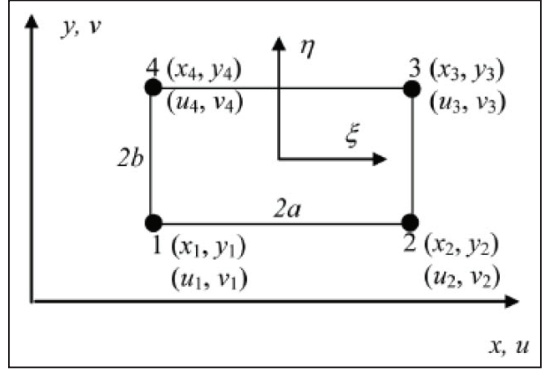

Figure 6. Four-node bilinear element used in simulations.

where $x_{i}, y_{i}$ are the global coordinates at the $i$ th node; $u_{i}$, $v_{i}$ are the displacements at the $i$ th node along the global $X$, $Y$ axes, respectively. $N_{i}(\xi, \eta)$ represents interpolation, or the shape function for the $i$ th node defined in natural coordinates. $\xi_{i}, \eta_{i}$ denote natural coordinates of the $i$ th element node. The nodal interpolation function $N_{i}(\xi, n)$ for the quadrilateral element is of the form:

$$
\begin{aligned}
& \left.\begin{array}{l}
x=\sum_{i=1}^{4} N_{i}(\xi, \eta) x_{i}, u=\sum_{i=1}^{4} N_{i}(\xi, \eta) u_{i} \\
y=\sum_{i=1}^{4} N_{i}(\xi, \eta) y_{i}, v=\sum_{i=1}^{4} N_{i}(\xi, \eta) v_{i}
\end{array}\right\}, \ldots \ldots . \\
& N_{i}(\xi, n)=\frac{1}{4}(1+\xi \xi \xi)\left(1+\eta_{i} \eta\right), \text { for } i=1,2,3,4 \ldots \ldots \ldots
\end{aligned}
$$

where $\xi_{\mathrm{i}}=-1$ for $i=1$ and $4, \xi_{i}=1$ for $i=2$ and $3, \eta_{i}=-1$ for $i=1$ and 2 , and $\eta_{i}=1$ for $i=3$ and 4 .

Infinitesimal strains (generally incremental strains are small and can be treated infinitesimal) at any point within the element are expressed as

$$
\left[\begin{array}{c}
\varepsilon_{x} \\
\varepsilon_{y} \\
\varepsilon_{x y}
\end{array}\right]=\left[\begin{array}{c}
\frac{\partial u}{\partial x} \\
\frac{\partial v}{\partial y} \\
\frac{\partial v}{\partial y}+\frac{\partial u}{\partial x}
\end{array}\right]=\left[\begin{array}{cc}
\frac{\partial}{\partial x} & 0 \\
0 & \frac{\partial}{\partial y} \\
\frac{\partial}{\partial y} & \frac{\partial}{\partial x}
\end{array}\right]\left[\begin{array}{l}
u \\
v
\end{array}\right]
$$

$$
\left[\begin{array}{l}
\varepsilon_{x} \\
\varepsilon_{y} \\
\varepsilon_{z}
\end{array}\right]=\left[\begin{array}{cc}
\frac{\partial}{\partial x} & 0 \\
0 & \frac{\partial}{\partial y} \\
\frac{\partial}{\partial y} & \frac{\partial}{\partial x}
\end{array}\right]
$$

$$
\begin{aligned}
& {\left[\begin{array}{cccccccc}
N_{1} & 0 & N_{2} & 0 & N_{3} & 0 & N_{4} & 0 \\
0 & N_{1} & 0 & N_{2} & 0 & N_{3} & 0 & N_{4}
\end{array}\right]\left[\begin{array}{c}
u_{1} \\
v_{1} \\
u_{2} \\
v_{2} \\
u_{3} \\
v_{3} \\
u_{4} \\
v_{4}
\end{array}\right], \ldots \ldots} \\
& \varepsilon=d u=d N q=B q
\end{aligned}
$$

where $B$ is the strain-displacement matrix; $q$ is the vector of nodal displacements. Hence, the final elastic stress-strain relationship becomes as follows ${ }^{34}$ :

$$
\sigma=D \varepsilon=D B q, \ldots \ldots \ldots \ldots \ldots
$$

where $D$ is the elastoplastic matrix defining mechanical properties of the material in terms of the Young's modulus and the Poisson's ratio. The governing equations and formulation procedure for the elastoplastic analysis are described in Dixit and Dixit. ${ }^{34}$ In this work, the ABAQUS/Explicit software package was used for simulations, implementing a largedeformation, nonlinear elastoplastic analysis.

\section{Constitutive equations of workpiece material}

Thermo-mechanical properties of the material undergoing plastic deformation are governed by respective constitutive equations. These equations comprise a yield criterion and a 
flow rule with strain-hardening. For a metal-cutting process, various plasticity models take into account the von Mises yield criterion and the Prandtl-Reuss flow rule to define the isotropic yielding and hardening. The realistic constitutive equations are an indispensable part of FE simulations.

The Johnson-Cook (J-C) model is the most widely used equation for defining the material behavior. The strain-rate sensitivity of 4340 hardened steel can be defined by the following equation ${ }^{35}$ :

$$
\bar{\sigma}=\left(A+B \varepsilon_{p}^{n}\right)\left[1+C \ln \left(\frac{\dot{\varepsilon}}{\dot{\varepsilon}_{0}}\right)\right]\left[1-\left(\frac{T-T_{\text {room }}}{T_{\text {room }}-T_{\text {melt }}}\right)^{m}\right], . .
$$

where $\bar{\sigma}$ denotes the equivalent stress, $A$ represents the initial yield stress, $n$ is the hardening exponent $B$ is the hardening modulus, $\varepsilon_{p}$ is plastic strain, $\dot{\varepsilon}$ is the reference strain rate, $T$ denotes operating temperature, $T_{\text {room }}$, and $T_{\text {melt }}$ are the room and melting temperatures, respectively. $C$ is the strain-rate coefficient and $m$ is the thermal softening coefficient. The Coulomb law of friction was used to define friction conditions at the tool-chip interface. A variable coefficient of friction related to sticking and sliding regimes in the secondary deformation zone was employed, while researchers often used an equivalent Coulomb's coefficient of friction. ${ }^{2-4,6,36}$ The effect of velocity on friction is not considered here. The value of the coefficient of friction was based on the experimental results reported by Sharma and Pandey. ${ }^{27}$

To account for a chip-separation process, the J-C ductile failure model was incorporated into the FE model. This ensured the movement of the cutting tool without any severe mesh distortion near the tool tip. The fracture strain $\left(\varepsilon^{f}\right)$ has the following form ${ }^{35}$ :

$$
\begin{aligned}
& \varepsilon^{f}=\left[D_{1}+D_{2} \exp \left(D_{3} \sigma^{*}\right)\right] \\
& {\left[1+D_{4} \ln \bar{\varepsilon}\right]\left[1+D_{5}\left(\frac{T-T_{\text {room }}}{T_{\text {melt }}-T_{\text {room }}}\right)\right] \ldots}
\end{aligned}
$$

where $\sigma^{*}$ is the hydrostatic stress, $D_{1}$ is the initial failure strain, $D_{2}$ is the exponential factor, $D_{3}$ is the triaxiality factor, $D_{4}$ is the strain-rate factor, and $D_{5}$ is the temperature factor. An element-deletion module along with the J-C damage scheme enabled to delete the elements that fractured during metal cutting. This resulted in chip separation from the workpiece and allowed the tool to progress further into it. The J-C material and damage properties of 4340 steel are presented in Tables 5 and 6 as reported by Johnson and Cook. ${ }^{37}$

Table 5. Johnson-Cook parameters for 4340 steel.

\begin{tabular}{ccccc}
\hline$A(\mathrm{MPa})$ & $B(\mathrm{MPa})$ & $N$ & $M$ & $C$ \\
\hline 792 & 510 & 0.26 & 1.03 & 0.014 \\
\hline
\end{tabular}

Source: Markopoulas. ${ }^{35}$
Table 6. Johnson-Cook damage parameters for 4340 steel.

\begin{tabular}{ccccc}
\hline$D_{1}$ & $D_{2}$ & $D_{3}$ & $D_{4}$ & $D_{5}$ \\
\hline 0.05 & 3.44 & -2.12 & 0.002 & 0.61 \\
\hline & & &
\end{tabular}

Source: Markopoulas. ${ }^{35}$

\section{Boundary conditions}

To perform cutting simulations, following boundary conditions were imposed on the tool and the workpiece (Figure 3):

- $\quad$ For the workpiece, its lowermost side AB was encastered, i.e., $u_{1}=u_{2}=u_{R 3}=0$.

- The displacement of the tool in the Y-direction was also constrained, i.e., $u_{2}=u_{R 3}=0$.

- The cutting tool was given the cutting velocity in the $\mathrm{X}$-direction, i.e., $u_{x}=-V$.

- $\quad$ During the CT process, $V=V_{c}$.

- During the UAT process, $V=V_{c}+a \omega \cos \omega t$, where $a$ denotes the amplitude of vibration, $\omega=2 \pi f, f$ is the frequency of vibration and $V_{c}$ is the cutting velocity in CT.

In ABAQUS software, the sinusoidal motion was approximated by the Fourier series to perform the simulations for UAT process. As discussed, texturing of the tool helps to reduce the coefficient of friction at the tool-chip interface; it was modeled by varying the frictional-contact conditions between the tool and the chip based on the experimental data. ${ }^{27}$

\section{Results and discussion}

The simulations were carried out for both CT and UAT processes using both the plane and textured cutting inserts. The main aim of the present paper is to analyze the levels of cutting forces, a governing parameter affecting the toolworkpiece interaction. The validation of the cutting forces was then implemented by comparing the calculated values with the experimental results obtained with the developed setup.

\section{Comparison of PCT and TCT cutting forces}

All FEM simulations were performed for two cutting toolsPCT and TCT - under identical conditions. Figure 7 presents both radial and tangential cutting forces as evaluated using the FEM analysis and experimentation. It could be inferred that fluctuations of the simulated cutting force is higher than that in the experimental data. The level of force fluctuations can be reduced by using a finer mesh size in the toolworkpiece zone and by increasing the number of increments and introducing more remeshing cycles between increments. However, a denser mesh will require more computational time and power. The force fluctuations are due to numerical errors; hence, the average cutting forces are compared for validating the FE model. 


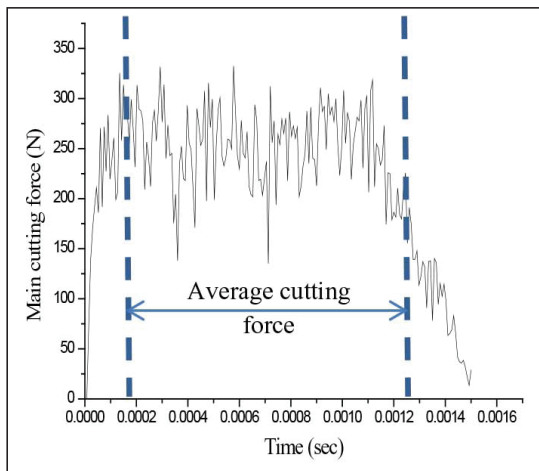

(a) Simulation: Average $=220.97 \mathrm{~N}$.

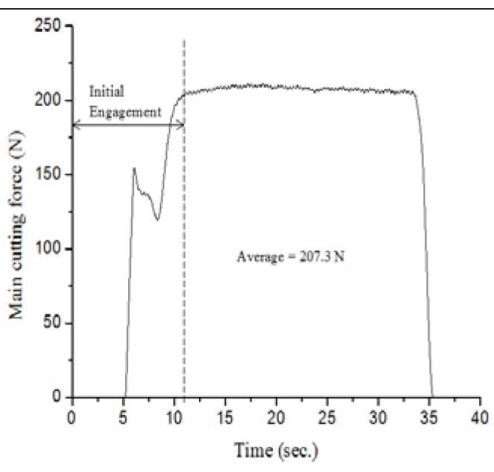

(b) Experimental: Average $=207.3$

$\mathrm{N}$.

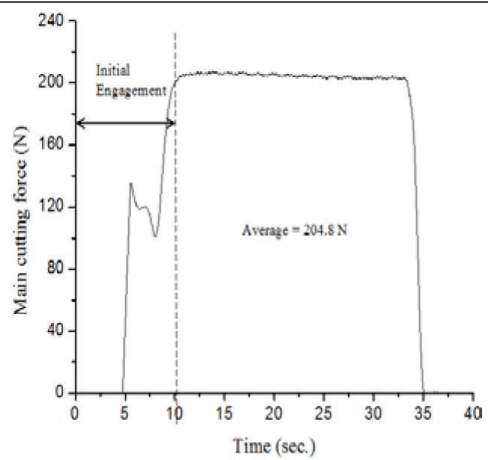

(d) Experimental: Average $=204.8$ $\mathrm{N}$.

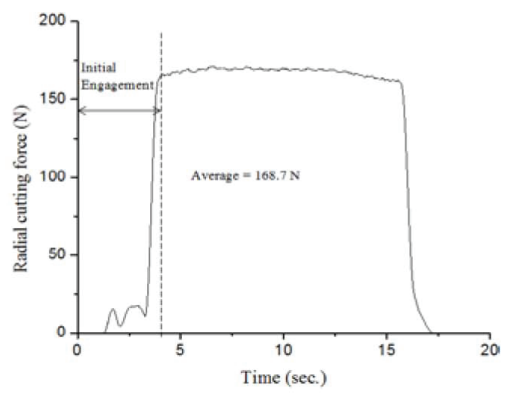

(f) Experimental: Average $=168.7$ $\mathrm{N}$.

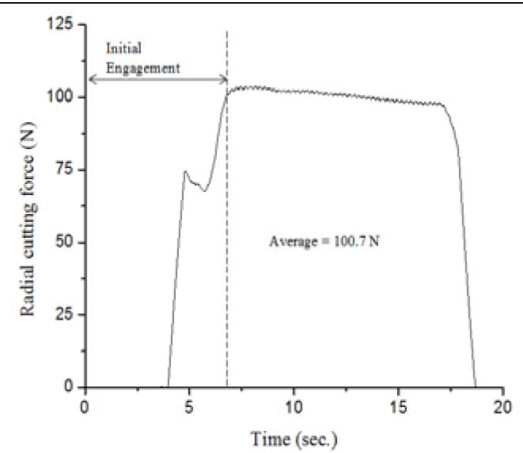

(h) Experimental: Average $=100.7$ $\mathrm{N}$ 


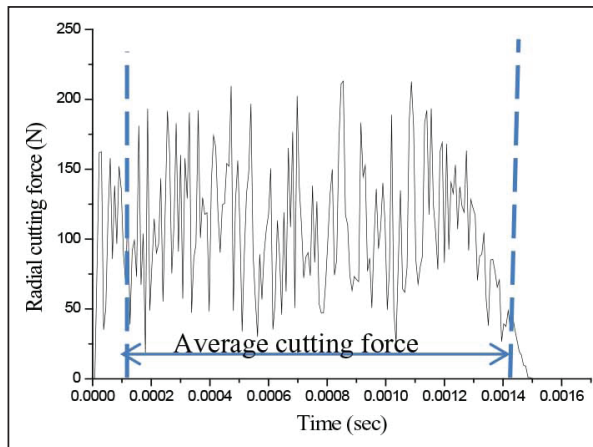

(i) Simulation: Average $=102.29 \mathrm{~N}$.

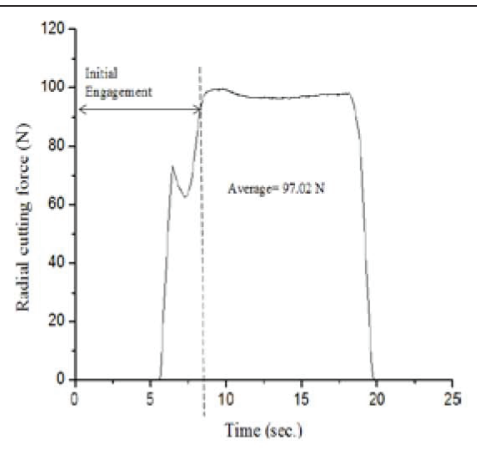

(j) Experimental: Average $=97.02 \mathrm{~N}$.

Figure 7. Comparative analysis for plane and textured cutting inserts for CT process.

Note: Panels (a), (c), (e), (g), and (i) present simulated cutting force, and (b), (d), (f), (h), and (j) present experimentally measured cutting force as measured using dynamometer under cutting conditions as per Table I.
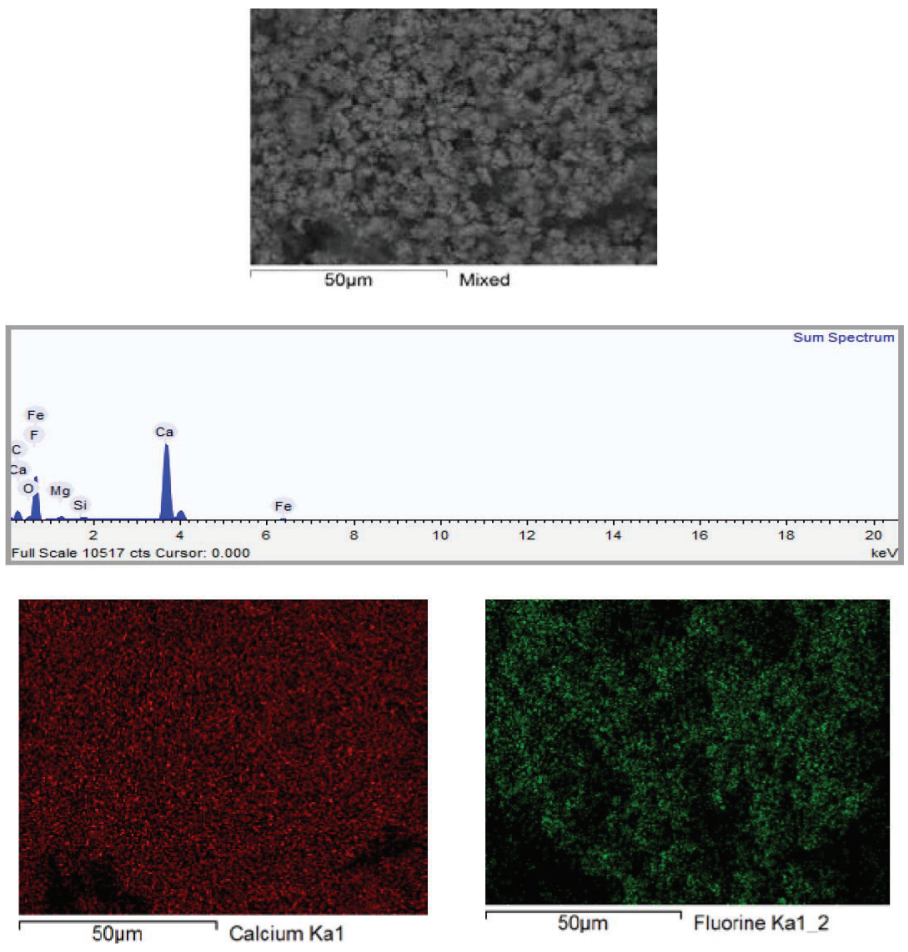

Figure 8. EDX mapping analysis of textured cutting insert at nose section.

The purpose of providing texturing on the plane cutting insert was to improve tribological conditions between two mating surfaces, i.e., the chip and the tool. Such texturing helps to reduce the frictional force owing to the reduction in tool-chip contact length. Besides, smearing of the solid lubricant entrapped into the textured pattern helps to lower the shear strength at the tool-chip interface. This was captured in simulations and validated with experiments by employing the plane and textured cutting inserts. The reduction in cutting forces in the TCT process can be explained by the diminished tool-chip contact length. Experimentally, the formation of the lubricating layer in the tribological contact was verified by implementing the energy dispersive X-ray (EDX) analysis at the topmost rake surface (Figure 8). It was found that $\mathrm{Ca}$ and $\mathrm{F}$ rose above the groove asperity, forming a thin lubricating layer at the tool-chip interface. This combined effect of reduction in the contact length and shear strength at the interface was found to reduce the frictional force, and, hence, all the components of the cutting forces also followed the decreasing trend during the TCT process. 


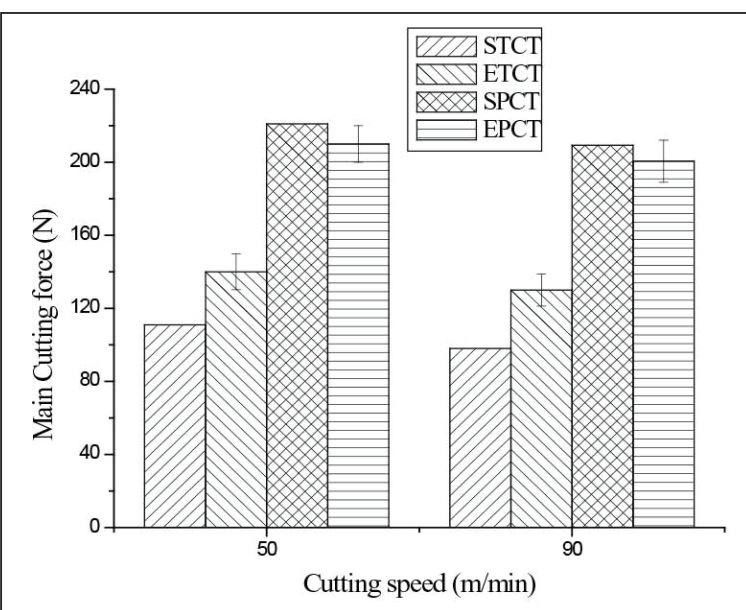

(a)

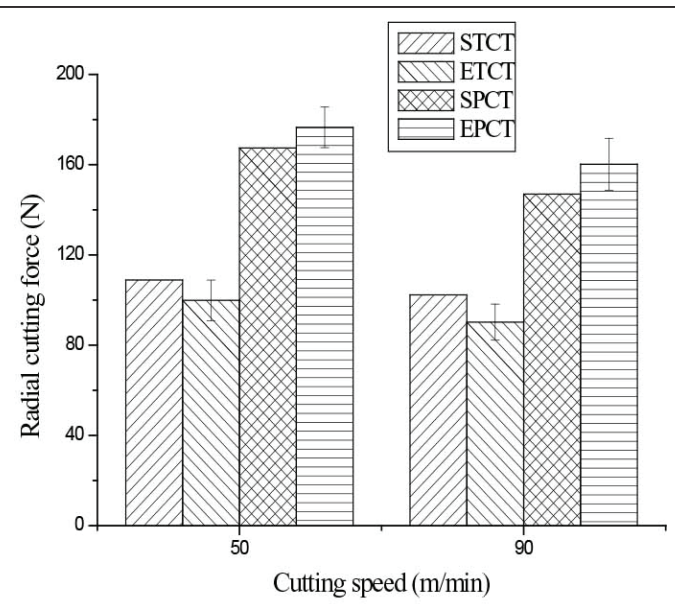

(b)

Figure 9. Validation of FE model with experimentation.

Note: $\mathrm{E}$ and $\mathrm{S}$ denote experiment and simulation, respectively, in abbreviation of processes.

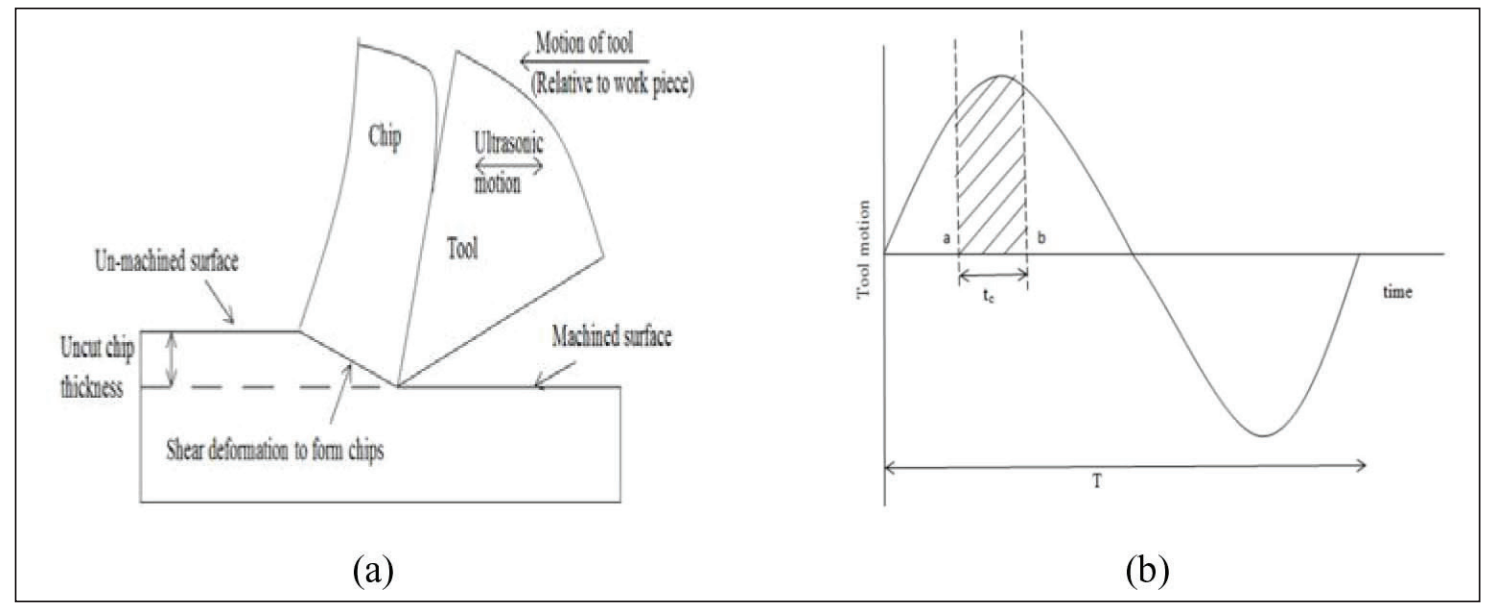

Figure 10. (a) Schematic movement of tool during UAT process. (b) Sinusoidal motion of cutting insert.

Note: Point $a$ indicates the point of engagement and point $b$ indicated point of disengagement.

Both the processes, namely, with TCT and PCT, were validated with the experimental data and are compared in Figure 9. The cylindrical turning experiments are approximated to validate the 2D FEM model based on the equivalent orthogonal machining process as proposed by $\mathrm{Ma}$ et al. $^{38}$ (refer to Appendix B). The maximum error between the simulated and experimentally measured levels of cutting forces is $21.4 \%$ in the main cutting force and $11.5 \%$ in the radial thrust force. It could be seen that the simulation results generally underestimated the values. The high value of the experimental forces can be mainly attributed to the nose radius (i.e., $0.4 \mathrm{~mm}$ ) of the cutting insert as compared to the sharp tool used in the FE simulation. The corner radius introduced bluntness and resulted in an increased contact area around the tool tip, which in turn, required a higher cutting force for material shearing.

\section{Comparison of PUAT and TUAT cutting forces}

To further enhance the machinability of 4340 steel, ultrasonic excitation was provided to the cutting insert to reduce the cutting force. It was reported that in the UAT process, the material is removed intermittently. For a large part of each cycle of vibration, the cutting tool is not in engagement with the workpiece (Figure 10). It engages only during a period corresponding to segment ab in Figure 10(b) over a complete cycle of vibration with time period $\mathrm{T}$. This, in turn, decreases the average cutting force over a complete cycle of vibration. To validate the numerical study, experimental analysis was performed by exciting vibration of the insert in the cutting direction (Figure 1). A potential mechanism, apart from the vibro-impact intermittent contact, could be an enhancement in dislocation movement leading to an effective lowering in 
yield stress of the workpiece material as proposed by Yao et al. ${ }^{39}$ During the application of the ultrasonic assistance to the cutting tool, the additional energy provided in the form of vibration helped to lower the energy barrier for the dislocation motion. ${ }^{39}$ This, in turn, lowered the yield strength of the workpiece according to the following equation.

$$
\Delta Y_{L}=Y_{o}-Y_{L}=K_{s} \sqrt{U_{L}}, \ldots \cdots \cdots
$$

where $Y_{o}$ and $Y_{L}$ denote the yield strength of the material in its surface layer without and with vibration, respectively. $K_{s}$ represents the factor related to acoustic softening and $U_{L}$ denotes the vibration-energy density.

It could be seen that with a growing ultrasonic power the vibration energy density increased and, hence, the yield strength of the workpiece material decreased. ${ }^{39}$ This facilitated plastic deformation of surface asperities; hence, in UAT the cutting tool required a lower level of cutting forces to remove the material. Still, the dry PUAT process could be further improved by using a lubricant. UAT performed with the textured cutting insert (TUAT) was employed for the first time by the authors to enhance the efficacy of the dry UAT process. Such inserts were found to reduce the cutting forces further ${ }^{40}$ due to a combined effect of lubrication by the use of $\mathrm{CaF}_{2}$ and the intermittent contact conditions at the toolchip interface. Figure 11 shows the cutting force fluctuations during the CT and UAT processes. It can be observed that there occurs a sudden drop in the cutting force component around $22 \mathrm{~s}$ of machining, i.e., when the ultrasonic vibrations were provided to the cutting insert. ${ }^{31}$

The level of cutting forces during the periods of noncontact should be zero. However, this could not be captured in the experimental studies as the sampling rate of force-data acquisition $(5000 \mathrm{~Hz})$ was lower than the frequency of ultrasonic vibration provided by the transducer, i.e., $19.8 \mathrm{kHz}$. To ensure the intermittent cutting mechanism,
FEM simulations of the UAT were performed (Figure 12). It could be inferred from the cutting-force variation that the cutting forces vanished at these stages of the process.

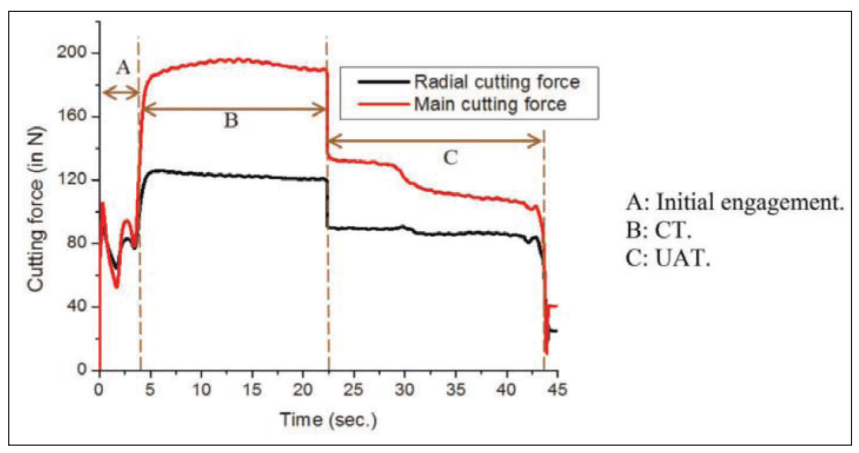

Figure II. Experimental cutting force variation in CT and UAT processes as captured by the dynamometer. ${ }^{31}$

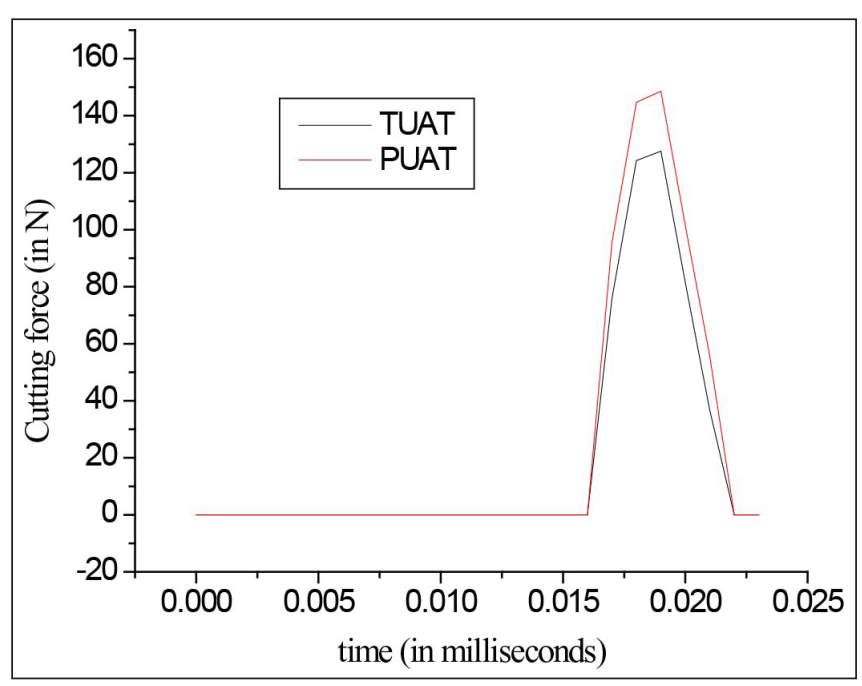

Figure I 2. Variation in cutting force during PUAT and TUAT processes.

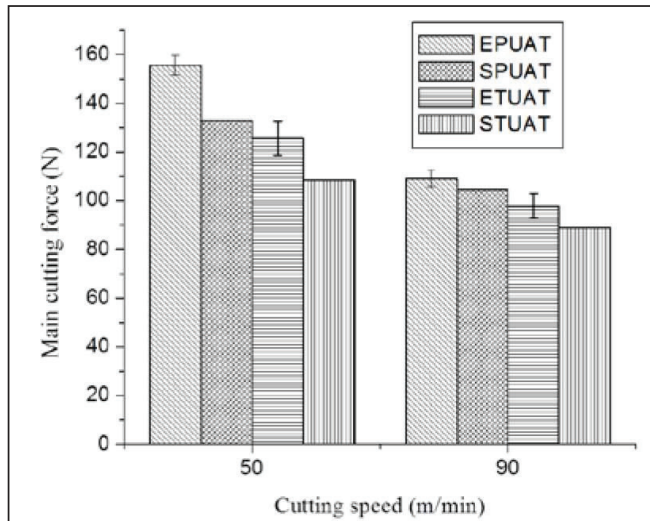

(a)

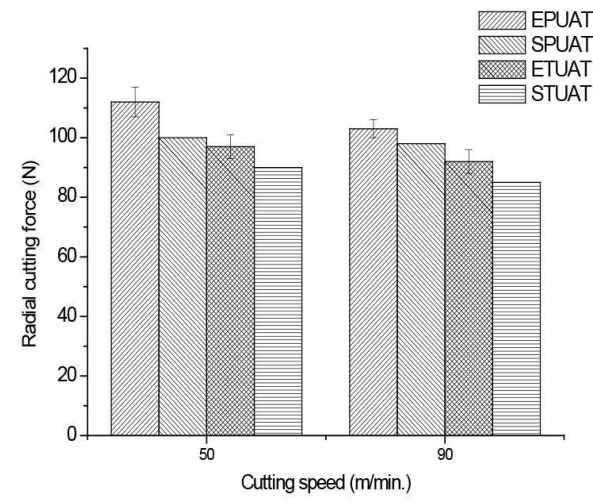

(b)

Figure 13. Comparison of experimental and numerical results for PUAT and TUAT processes.

Note: $\mathrm{E}$ and $\mathrm{S}$ denote experiment and simulation, respectively, in abbreviation of processes. 
According to the Courant-Friedrichs-Lewy (CFL) condition for explicit simulations of dynamics of UAT, the maximum time increment should be smaller than the time taken by the fastest moving wave to travel through the smallest element. For the present simulation, with an approximate global mesh size of $0.005 \mathrm{~mm}$, a decrease in the maximum time increment resulted in an excessive element distortion. A further decrease in the global mesh size accompanied with senility analysis could result in better approximation of the cutting forces. Hence, the current FEM model has a limitation of accurately predicting the tool-workpiece contact ratio due to the used minimum element size.

To further enhance the efficacy of the UAT process, FE simulations were also performed for the textured cutting insert. It could be seen that the cutting forces further decreased in this case compared to those for the plane insert (Figure 12). This could be explained by the fact that texturing helped to reduce the frictional force between the chip and the tool's rake surface. In UAT performed with a plane tool, aerodynamic lubrication (i.e., the lubrication occurring because of toolchip separation) is the only factor diminishing the coefficient of friction. In the TUAT process, formation of a thin layer of $\mathrm{CaF}_{2}$ results in further reduction, alongside aerodynamic lubrication, of the coefficient of friction. As a result, the level of cutting forces in this process is lower than that for the other processes compared.

The comparative analysis for the PUAT and TUAT processes is presented in Figure 13 (notation: EPUAT, experimental PUAT; SPUAT, simulated PUAT; ETUAT, experimental TUAT; and STUAT, simulated TUAT). A decrease in the cutting forces with increased cutting speed is attributed to thermal softening due to more adiabatic conditions in the process zone. Moreover, at higher cutting speed, less time is provided for heat dissipation through the material, ${ }^{9}$ resulting in a rise of the cutting temperature in the machining zone and, subsequently, decreased yield strength of the workpiece material. This in turn decreased cutting forces with a rise in the cutting speed..$^{7-9}$ Also, it could be seen that the calculated forces were lower than those measured in the experiments.

An underestimate of the cutting forces in the UAT process was found to be $14.6 \%$ in the main cutting force and $13.4 \%$ in the radial component of cutting force. One reason for this is that in actual experimental conditions, variable friction occurs in the secondary zone of deformation; however, during simulations, a constant coefficient of friction was assumed.

\section{Conclusions}

2D FEM models for conventional and UAT with plane and textured cutting inserts were successfully developed in ABAQUS/Explicit. The experimental findings for PCT, TCT, PUAT, and TUAT were used to validate the cutting forces evaluated with FE simulations. The following conclusions can be drawn from the implemented 2D FE simulations:
1. Experimental and numerical studies carried out for the CT and UAT processes demonstrated the capability of UAT to lower the cutting forces.

2. The effect of lubrication was studied by comparison of simulations for the CT and UAT processes. The use of textured cutting inserts demonstrated the reduction in frictional forces due to formation of the thin lubricating layer at the tool-chip interface evaluated experimentally.

3. The implemented FEM analysis of the PUAT and TUAT processes allowed the assessment of reduction in the cutting forces during the noncontact time of UAT.

4. The cutting-force data obtained from the simulations were validated with the experimental findings with an underestimate of $14.6 \%$ in the main cutting force and $13.4 \%$ in the radial component. There was a good qualitative agreement, but significant quantitative difference between simulated and experimental results. Hence, there is a need to carry out research for faster and accurate simulation of machining processes.

\section{Acknowledgements}

The authors gratefully acknowledge financial support from EPSRC (UK) through grant EP/K028316/1 and DST (India) through grant DST/RC-UK/14-AM/2012, under the project titled 'Modeling of Advanced Materials for Simulation of Transformative Manufacturing Process'.

\section{Declaration of conflicting interests}

The authors declared no potential conflicts of interest with respect to the research, authorship, and/or publication of this article.

\section{Funding}

The authors received no financial support for the research, authorship, and/or publication of this article.

\section{Appendix A}

The sonotrode serves as a means of transmitting the vibratory energy from the transducer end to the other end, by providing a means for the wave propagation. As very high amplitude is predominant in machining there occurs a considerable stress load to the sonotrode. Therefore, materials used for the fabrication of sonotrode should have high impact strength and low absorption. Out of the various prescribed materials for the sonotrode manufacturing stainless steel (SS316) was used for the present work because of its easy availability and less cost as compared to titanium alloy. Sonotrodes could be manufactured in various shapes and dimensions. However, taking into consideration the ease in manufacturing stepped horn was made for providing vibration to the cutting insert. 
For a stepped horn with circular cross-section, the design inputs required for the sonotrode calculations are as follows:

1. Young's modulus $(E)=192 \mathrm{GPa}$.

2. Density $(\rho)=8000 \mathrm{~kg} \mathrm{~m}^{-3}$.

3. Input amplitude $\left(a_{\text {in }}\right)=5 \mu \mathrm{m}$.

4. Frequency $(f)=20 \mathrm{kHz}$.

5. Input diameter $\left(D_{1}\right)=30 \mathrm{~mm}$.

6. Output diameter $\left(D_{2}\right)=15 \mathrm{~mm}$.

The axial mode of sound velocity $C_{a}=\sqrt{ }(E / \rho)=4898.97 \mathrm{~m} \mathrm{~s}^{-1}$.

The axial mode wavelength $\lambda=C_{a} / f=245.6 \mathrm{~mm}$.

Total length of sonotrode $L=\lambda / 2=122.8 \mathrm{~mm}$.

By considering the stepped horn of equal length $L_{1}=L_{2}$ $=L / 2=61.4 \mathrm{~mm}$.

\section{Appendix B}

For the model validation developed for orthogonal cutting, the cutting forces in 3D cutting are approximated by an equivalent orthogonal machining process as suggested by Ma et al. ${ }^{38}$ The turning operation with a curved edge is approximated with the straight cutting edge to develop an equivalent orthogonal process. From Figure B1, the following relations between the two processes can be developed ${ }^{38}$ :

$$
\begin{aligned}
& b=\frac{d}{\cos \left(C_{s}\right)}, \ldots \ldots \ldots \ldots \ldots \\
& t=f \cos \left(C_{s}\right), \ldots \ldots \ldots \ldots \ldots \\
& F_{y}=\sqrt{F_{f}^{2}+F_{t}^{2}}, \ldots \ldots \ldots \ldots \ldots \\
& F_{y}, F_{x}, \ldots \ldots \ldots \ldots \ldots
\end{aligned}
$$

where $f$ represents the feed rate, $d$ is the depth of cut and $C_{s}$ denotes the side cutting edge angle. The three cutting-force components in turning $\left(F_{f}, F_{t}, F_{c}\right)$ are converted into two force components in orthogonal machining $\left(F_{y}, F_{x}\right)$ using the aforesaid equations. The shaded area in Figure B1 denotes the uncut chip's cross-section in the equivalent orthogonal model.

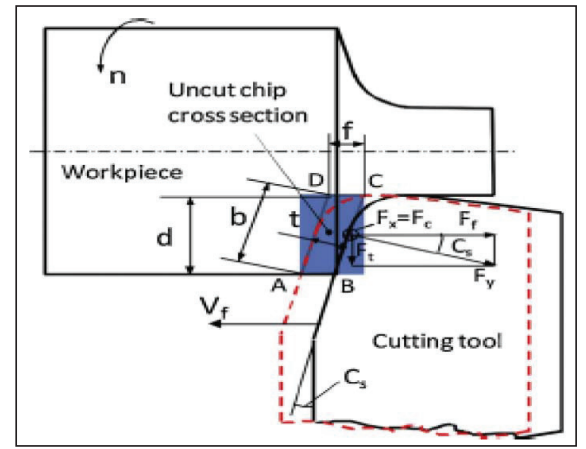

Figure BI. Geometry for conversion of cylindrical turning into orthogonal machining.

Source: $M a$ et al. ${ }^{38}$

\section{References}

1. Skelton RC. Effect of ultrasonic vibration on the turning process. Inter J Mach Tool Des Resear 1969; 9: 363-374.

2. Mitrofanov AV, Babitsky VI, Silberschmidt VV. Finite element simulations of ultrasonically assisted turning. Comp Mat Sci 2003; 28: 645-653.

3. Mitrofanov AV, Babitsky VI, Silberschmidt VV. Finite element analysis of ultrasonically assisted turning of Inconel 718. $J$ Mater Process Technol 2014; 153: 233-239.

4. Babitsky VI, Mitrofanov AV, Silberschmidt VV. Ultrasonically assisted turning of aviation materials: simulations and experimental study. Ultrasonics 2004; 42: 81-86.

5. Muhammad R, Maurotto A, Demiral M, Roy A, Silberschmidt VV. Thermally enhanced ultrasonically assisted machining of Ti alloy. CIRP J Manuf Sci Technol 2014; 7: 159-167.

6. Ahmed N, Mitrofanov AV, Babitsky VI, Silberschmidt VV. Analysis of forces in ultrasonically assisted turning. $J$ Sound Vib 2007; 308: 845-854.

7. Patil S, Joshi S, Tewari A, Joshi SS. Modelling and simulation of effect of ultrasonic vibrations on machining of Ti6Al4V. Ultrasonics 2014; 54: 694-705.

8. Muhammad R, Roy A, Silberschmidt VV. Finite element modelling of conventional and hybrid oblique turning processes of titanium alloy. Procedia CIRP 2013; 8: 510-515.

9. Nategh MJ, Eng M. A machining force model developed for ultrasonic vibration-assisted turning through statistical analysis of influential parameters. Mech Aerospace Eng $J$ 2009; 4: 83-91.

10. Maurotto A, Roy A, Babitsky VI, Silberschmidt VV. Analysis of machinability of Ti- and Ni-based alloys. Solid State Phenom 2012; 188: 330-338.

11. Maurotto A, Muhammad R, Roy A, Silberschmidt VV. Enhanced ultrasonically assisted turning of a $\beta$-titanium alloy. Ultrasonics 2013; 53: 1242-1250.

12. Wu Z, Deng J, Zhang H, Lian Y, Zhao J. Tribological behavior of textured cemented carbide filled with solid lubricants in dry sliding with titanium alloys. Wear 2012; 292: 135-143.

13. Ze W, Jianxin D, Yang C, Youqiang X, Jun Z. Performance of the self-lubricating textured tools in dry cutting of Ti-6Al-4V. Int J Adv Manuf Technol 2012; 62: 943-951.

14. Xing Y, Deng J, Zhao J, Zhang G, Zhang K. Cutting performance and wear mechanism of nanoscale and microscale textured A12O3/TiC ceramic tools in dry cutting of hardened steel. Int $J$ Refract Met Hard Mater 2014; 43: 46-58.

15. Sugihara T, Enomoto T. Development of a cutting tool with a nano/micro-textured surface-Improvement of anti-adhesive effect by considering the texture patterns. Precis Eng 2009; 33: 425-429.

16. Koshy P, Tovey J. Performance of electrical discharge textured cutting tools. CIRP Ann Manuf Technol 2011; 60: 153-156. 
17. Xie J, Luo MJ, Wu KK, Yang LF, Li DH. Experimental study on cutting temperature and cutting force in dry turning of titanium alloy using a non-coated micro-grooved tool. Int J Mach Tools Manuf 2013; 73: 25-36.

18. Jianxin D, Ze W, Yunsong L, Ting Q, Jie C. Performance of carbide tools with textured rake-face filled with solid lubricants in dry cutting processes. Int J Refract Met Hard Mater 2012; 30: $164-172$.

19. Kawasegi N, Sugimori H, Morimoto H, Morita N, Hori I. Development of cutting tools with microscale and nanoscale textures to improve frictional behavior. Precis Eng 2009; 33: $248-254$.

20. Jiang W. Bio-inspired self-sharpening cutting tool surface for finish hard turning of steel. CIRP Ann-Manuf Technol 2014; 63: 517-520.

21. Obikawa T, Kamio A, Takaoka H, Osada A. Micro-texture at the coated tool face for high performance cutting. Int $J$ Mach Tools Manuf 2011; 51: 966-972.

22. Wenlong $\mathrm{S}$, Jianxin $\mathrm{D}, \mathrm{Ze} \mathrm{W}$, et al. Cutting performance of cemented-carbides-based self-lubricated tool embedded with different solid lubricants. Int J Adv Manuf Technol 2010; 52: 477-485.

23. Zahedi SA, Demiral M, Roy A, Silberschmidt VV. FE/SPH modelling of orthogonal micro-machining of FCC single crystal. Com Mat Sci 2013; 78: 104-109.

24. Ahmed N, Mitrofanov AV, Babitsky VI, Silberschmidt VV. 3D finite element analysis of ultrasonically assisted turning. Com Mat Sci 2007; 39: 149-154.

25. Mitrofanov AV, Babitsky VI, Silberschmidt VV. Thermomechanical finite element simulations of ultrasonically assisted turning. Com Mat Sci 2005; 32: 463-471.

26. Goel S, Martinez FD, Chavoshi SZ, Khatri N, Giusca C. Molecular dynamics simulation of the elliptical vibration-assisted machining of pure iron, J Micromanufac 2018; 1(1): 6-19

27. Sharma V, Pandey PM. Study of ultrasonic assisted turning of 4340 steel with plane and self-lubricating cutting inserts. Proceedings of the 2016 Manufacturing Science and Engineering Conference MSEC2016, Virginia Tech, Blacksburg, USA.

28. Sharma V, Pandey PM. Optimization of machining and vibration parameters for residual stresses minimization in ultrasonic assisted turning of 4340 hardened steel. Ultrasonics 2016; 70: 172-182.
29. Sharma V, Pandey PM. Comparative study of turning of 4340 hardened steel with hybrid textured self-lubricating cutting inserts. Mat Manuf Process 2016; 31: 1904-1916.

30. Sharma V, Pandey PM. Geometrical design optimization of hybrid textured self-lubricating cutting inserts for turning 4340 hardened steel. Int J Adv Manuf Technol 2016; 89: 1575-1589, http://doi.org/10.1007/s0017-016-9163-6

31. Sharma V, Pandey PM. Experimental investigations and statistical modeling of surface roughness during ultrasonicassisted turning with self-lubricating cutting inserts, Proc. of Institution of Mech. Engg., Part E: J Process Mechanical Engg 2018; 232: 709-722.

32. Johnson GR, Cook WH. A constitutive model and data for metals subjected to large strains, high strain rates and high temperatures. 7th International Symposium on Ballistics, The Hague 1983; 541-547.

33. Dixit US. Finite element methods for engineers. Cengage Learning India, Noida 2009. ISBN: 9788131509816.

34. Dixit PM, Dixit US. Modelling of metal forming and machining processes. London: Springer-Verlag; 2008. ISBN 978-1-84800-188-6.

35. Markopoulas AP. Finite element methods in machining processes. London: Springer-Verlag; 2013. ISBN: 978-1-4471-4329-1.

36. Dixit US, Yadav V, Narayanan RG, Bhardwaj N. Friction in micromanufacturing, J Micromanufac 2018; 1(1): 76-91

37. Johnson GR, Cook WA. Fracture characteristic of three metals subjected to various strains, strain rates, temperatures and pressures. Eng Fract Mech 1985; 21: 31-48.

38. Ma J, Duaong NK, Lei S. Numerical investigation of the performance of microbump textured cutting tool in dry machining of AISI 1045 steel. J Manuf Process 2015; 19: 194-204.

39. Yao Z, Mei D, Chen Z. Modeling of metallic surface topography modification by high-frequency vibration. J Sound Vib 2015. doi: http://dx.doi.org/10.1016/j.jsv.2015.10.037

40. Sharma V, Pandey PM. Recent advances in turning with textured cutting tools: A review. J Cleaner Production 2016; 137: 701-715.

41. Prete AD, Filice L, Umbrello D. Numerical simulation of machining nickel-based alloys. Procedia CIRP 2013; 8: $540-545$ 